\title{
A Robust Quasi-Superhydrophobic Ceria Coating Prepared Using Air-plasma Spraying
}

DOI:

10.1111/jace. 16005

\section{Document Version}

Accepted author manuscript

Link to publication record in Manchester Research Explorer

\section{Citation for published version (APA):}

Xiao, P. (2018). A Robust Quasi-Superhydrophobic Ceria Coating Prepared Using Air-plasma Spraying. Journal of the American Ceramic Society. https://doi.org/10.1111/jace.16005

\section{Published in:}

Journal of the American Ceramic Society

\section{Citing this paper}

Please note that where the full-text provided on Manchester Research Explorer is the Author Accepted Manuscript or Proof version this may differ from the final Published version. If citing, it is advised that you check and use the publisher's definitive version.

\section{General rights}

Copyright and moral rights for the publications made accessible in the Research Explorer are retained by the authors and/or other copyright owners and it is a condition of accessing publications that users recognise and abide by the legal requirements associated with these rights.

\section{Takedown policy}

If you believe that this document breaches copyright please refer to the University of Manchester's Takedown Procedures [http://man.ac.uk/04Y6Bo] or contact uml.scholarlycommunications@manchester.ac.uk providing relevant details, so we can investigate your claim.

\section{OPEN ACCESS}




\section{A Robust Quasi-Superhydrophobic Ceria Coating Prepared Using Air-plasma Spraying}

Lingyue $\mathrm{Hu}^{\mathrm{a}}$, Xuefeng Song ${ }^{\mathrm{a}}$, Dongliang Jin ${ }^{\mathrm{a}}$, Chen Xing ${ }^{\mathrm{a}}$, Xiao Shan ${ }^{\mathrm{a}}$, Xiaofeng Zhao $^{\mathrm{a},{ }^{*}, \text { Fangwei Guo }}{ }^{\mathrm{a}}$ and Ping Xiao ${ }^{\mathrm{a}, \mathrm{b}}$

\section{ABSTRACT}

Hydrophobic coatings that could survive in harsh environment have a wide range of applications from industry to houseware. However, the state of the art polymer based coatings cannot meet such requirements due to their low melting point and poor wear resistance. In this study, we reported a plasma sprayed ceramic coating made of ceria with exceptional hydrophobicity, high temperature stability and good wear resistance. The coating exhibited a water contact angle (WCA) up to $139^{\circ}$, due to the intrinsic hydrophobicity of ceria and unique surface morphology produced by plasma spraying. The WCA only slightly decreased to $131^{\circ}$ after annealing at $773 \mathrm{~K}$. In addition, the polished coating (WCA $\sim 116^{\circ}$ ) was still more hydrophobic than the sintered bulk specimen (WCA $\sim 95^{\circ}$ ) with the same composition and roughness, which can be attributed to the surface chemistry change induced by $\mathrm{Ar}^{+}$ion bombing by plasma. It is believed that such robust hydrophobic coating should have great potential in

\footnotetext{
a Shanghai Key Laboratory of Advanced High-temperature Materials and Precision Forming, School of Material Science and Engineering, Shanghai Jiao Tong University, Shanghai 200240, China.

${ }^{\mathrm{b}}$ School of Materials, University of Manchester, MSS Tower, Manchester M13 9PL, UK.

* Corresponding author. Xiaofeng Zhao, Email address: xiaofengzhao@ sjtu.edu.cn
} 
engineering application. 


\section{Introduction}

The design and synthesis of hydrophobic surfaces with high water contact angles (WCA) have attracted extensive interests in recent years ${ }^{1-6}$. These surfaces are widely used in various applications from industry to home for their unique properties ${ }^{7-14}$. In many cases, organic materials, such as polytetrafluoroethylene (PTFE) ${ }^{4,8,10}$ or inorganic surfaces modified by organic materials, e.g., fluoroalkyl siloxane, ${ }^{4,15}$ are wildly used for hydrophobic coating due to their low surface energy, low cost, easy production process, and good corrosion resistance ${ }^{16}$. However, the organic coatings are not robust enough to harsh environments ${ }^{17}$. Specifically, they suffer from poor mechanical durability ${ }^{18}$, low wear resistance and poor thermal stability ${ }^{19}$. A few inorganic metal oxides, such as the $\mathrm{TiO}_{2}{ }^{20,21}, \mathrm{ZnO}^{22}$, and $\mathrm{ZrO}_{2}{ }^{23}$ have been explored, which show better mechanical durability than organic materials. However, the critical issue is that the hydrophobicity of $\mathrm{TiO}_{2}$ and $\mathrm{ZnO}$ coating could not be retained after UV exposure, or turned to be hydrophilic after high temperature annealing.

Azimi et $\mathrm{al}^{24}$ demonstrated that the rare earth oxides (REOs) show intrinsic hydrophobicity and thermal stability due to their unique electronic structure, where the filled $5 \mathrm{~s} 2 \mathrm{p} 6$ outer shell shields the unfilled inner $4 \mathrm{f}$ orbitals. This electronic structure decreases the tendency to interact with water molecules, which contributes to hydrophobicity. Although the REOs established a new family of hydrophobic material, compared with coating, bulks have more restriction for practical applications. It is wellknown that increasing the surface roughness significantly benefits to the 
hydrophobicity of intrinsically hydrophobic materials ${ }^{25-27}$. Zenkin et $\mathrm{al}^{24,28}$ fabricated REOs films using sputtering. Oh et $\mathrm{al}^{29}$ employed atomic layer deposition technique to prepare hydrophobic REOs film. Cho et $\mathrm{al}^{30}$ prepared REOs by hydrothermal method. Otherwise, glancing angle deposition ${ }^{31,}{ }^{32}$, electrodeposition ${ }^{33}$ and pre-seeding interfacial polymerization method ${ }^{34}$ were also used to fabricate ceria coating. But these methods usually have relatively low deposition efficiency or high cost, and thus restricts their engineering applications.

Compared to other coating processes, such as electroplating, physical and chemical vapor deposition, air plasma spray (APS) is a versatile coating technique and provides thick coatings (thickness range from 20 microns to several $\mathrm{mm}$ ), over a large area, or complex shape at high deposition rate, which has been widely employed to fabricate coatings in industry, e.g., thermal barrier coatings for aeroengine and gas turbines, wear resistant coating for oil and gas industry, etc. ${ }^{35}$. Owing to the high temperature, the ceria whose melting temperature is as high as $2670 \mathrm{~K}$ can be easily molten, which ensure the high deposition efficiency. Otherwise, the high spraying speed produces many semi-molten powders. The deposition of the fully molten and the semi-molten ceria powders may directly create a dual scale roughness surface. To enhance the thermal stability of hydrophobic coating and avoid the spallation of the coating at high temperature, the structure of the thermal barrier coating which has a bond coat is imitated. Among the REOs, ceria $\left(\mathrm{CeO}_{2}\right)$ has attracted particular interest due to its chemical stability, relatively low $\operatorname{cost}^{36}$. In addition, as ceramics, ceria has a higher hardness and thus more wear resistant than organic based coatings. It is expected that 
the ceria coating produced by APS should have a superior hydrophobicity, high temperature stability, and wear resistance. However, this has never been reported to date.

Therefore, the objective of this study is to investigate the hydrophobic behavior of ceria coating prepared by APS. The hydrophobicity was evaluated through the water contact angle measurements. The ceria sintered bulk was also prepared and compared with the coating to identify the effect of plasma spraying on the hydrophobicity. X-ray photoelectron spectroscopy (XPS) was employed to detect the chemical bonding of the specimen surface. In addition, the hydrophobic mechanism of APS ceria coating was discussed in relation to the surface chemistry and morphology induced by plasma.

\section{Experimental Section}

\subsection{Preparation of APS ceria coating.}

The ceria coating were fabricated using a APS system, which consisted of a ceria top coat and a NiCoCrAlY bond coat on Hastelloy-X substrate, with a dimension of $50 \times 50 \times 5 \mathrm{~mm}^{3}$.The use of the bond coat which is about $153 \mu \mathrm{m}$ thick is to improve the adherence between the ceria coating which is about $145 \mu \mathrm{m}$ thick and the metallic substrate. Commercially ceria and NiCoCrAlY (Amdry 365-2, Sulzer Metco, Switzerland) spherical powder were used as the feedstock materials. The spherical raw ceria powder has a nominal size distribution of $30-75 \mu \mathrm{m}$. Prior to the deposition, the substrate was grit-blasted and cleaned in acetone. Argon was used as the powder carrier gas. The fabrication parameters were summarized in Table 1. 
Table 1 Spraying Parameters used for deposition of the ceria coating

\begin{tabular}{lll}
\hline Parameters & Ceria & Bond coat \\
\hline Spray distance (mm) & 100 & 90 \\
Current (mA) & 500 & 400 \\
Ar gas flow (L/min) & 60 & 40 \\
$\mathrm{H}_{2}$ gas flow (L/min) & 9 & 5 \\
Feed rate $(\mathrm{g} / \mathrm{min})$ & 20 & 15 \\
\hline
\end{tabular}

To investigate the effect of plasma spraying on the hydrophobicity, the sintered bulk specimen were prepared using the same ceria powder., which was cold-pressed into a disk pellet ( $30 \mathrm{~mm}$ in diameters, $3 \mathrm{~mm}$ thick), without any binding additives. The sintering was performed in a chamber furnace (Carbolite, UK) at $1873 \mathrm{~K}$ for 4 hours. Then the surface of the sintered specimens were polished to a roughness of $0.23 \mu \mathrm{m}$.

\subsection{Wetting property and stability of ceria coating.}

Hydrophobic properties of the samples were evaluated by dipping a distilled water droplet with a volume of $10 \mu \mathrm{L}$ to the coating surface. A contact angle instrument (JC2000C4, Shanghai Zhongchen, China) was employed to measure the water contact angle. For each specimen, at least five measurements were conducted at random positions on the coating surface at room temperature. To test the thermal stability, the coating was annealed at $773 \mathrm{~K}$ for 2 hours in air, and furnace-cooled to the room temperature, and the contact angles were immediately measured after cooling. The water contact angles and the roughness were recorded when reducing the roughness by 
grinding the coating against a surface of abrasive silicon carbide until the substrate was exposed.

\subsection{Characterizations of the ceria coating.}

The morphologies of the samples were characterized using a scanning electron microscopy (SEM, Quanta 200, FEI). The roughness were measured using an optical profilometer (Zygo Zegage). At least 5 areas were tested on each sample. The roughness was characterized by the arithmetic mean roughness, $\mathrm{Ra}$. The surface chemistry of the samples were analyzed by XPS (ESCALAB 250, Thermo Scientific) with a $1486.6 \mathrm{eV}$ Al-K $\alpha$ monochromatic source. The spectra were fitted with a Gaussian-Lorentzian function using Casa software. The phase compositions were analyzed using X-ray diffraction (XRD, Ultimo IV, Riau, Japan) over a two theta angles $20-60^{\circ}$ at a $5 \% \mathrm{~min}$ scanning speed ( $\mathrm{Cu}-\mathrm{K} \alpha$ radiation). To analyze adsorbed species on samples, Fourier transform infrared (FT-IR) spectroscopy (Nicolet 6700, America) was used.

\section{Results}

\subsection{Microstructure of the ceria coating}



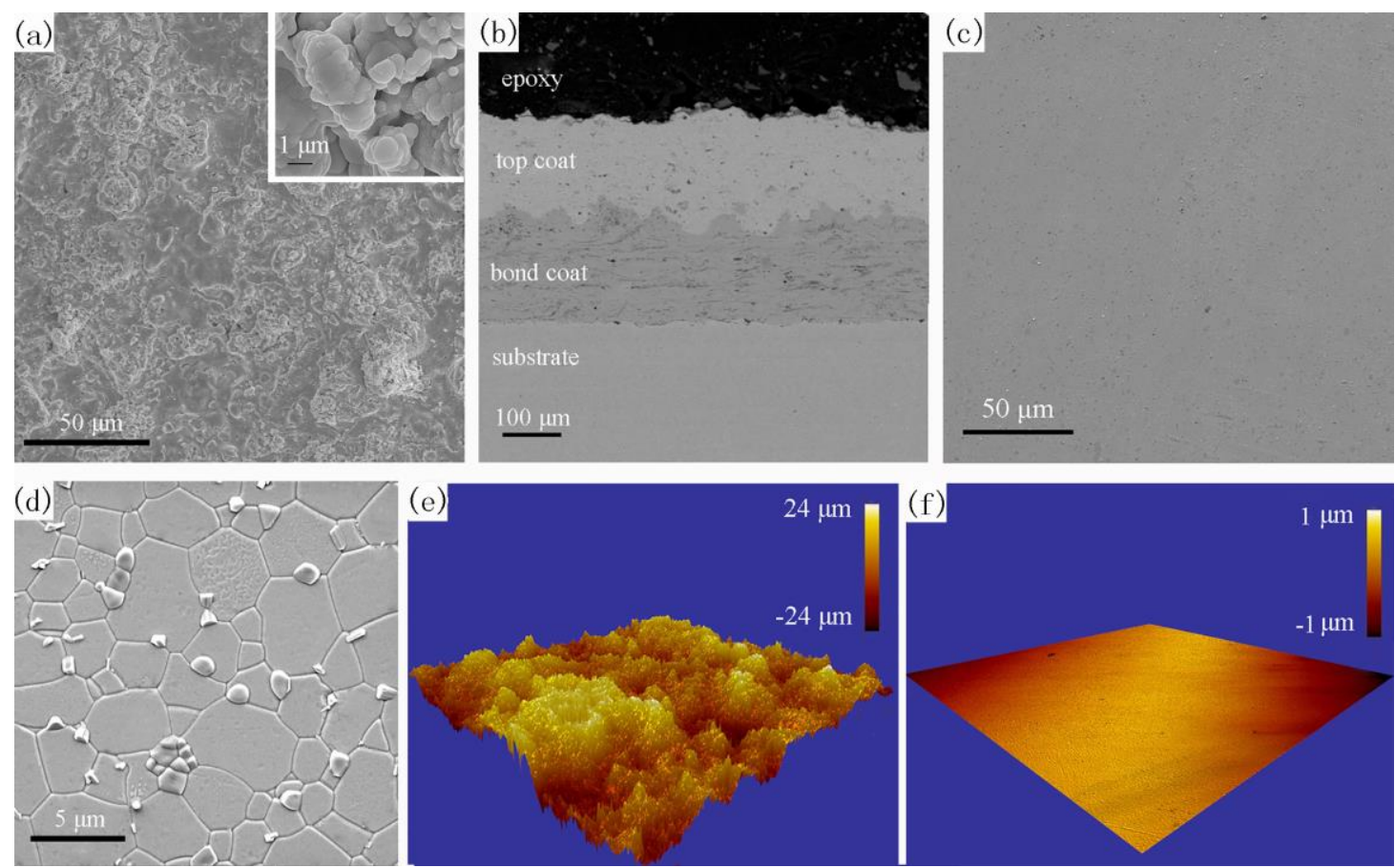

Fig. 1. Morphologies of the samples. (a) the surface morphology of the APS ceria coating, the inset is enlarged view of selected area, (b) cross sectional view of the APS coating, (c) and (d) the surface morphology of the sintered bulk, in (d) the bulk was thermal etched to observe the grain size, (e) 3D surface profile of the coating, and (f) 3D surface profile of the bulk.

The surface morphology of the coating prepared using APS is shown in Fig. 1a. The surface has a dual scale structure, which is composed of large particles (about $10 \mu \mathrm{m}$ ) and small islands (less than $1 \mu \mathrm{m}$ ) surrounded (the inset). This type of microstructure is similar to the surface of lotus leaf. It is believed that the particle size distribution of the raw powders and the partly melted powders play the important roles on the formation of dual scale structure. Fig. 1b gives the cross-section view of the coating which consists of a ceria top coat (thickness of $145 \mu \mathrm{m}$ ) and a NiCoCrAlY bond coat (153 $\mu \mathrm{m}$ thick) on substrate. Fig 1c and 1d gives the surface morphology of the polished sintered bulk. In Fig. 1d, the bulk was thermal etched at $1673 \mathrm{~K}$ for 2 hours to observe 
the grain size. The mean grain size is about $2.5 \mu \mathrm{m}$. As shown in Fig. 1e and 1f, the surface roughness of APS coating $(\mathrm{Ra}=4.89 \pm 0.09 \mu \mathrm{m})$ is larger than that of the sintered bulk $(\mathrm{Ra}=0.23 \pm 0.01 \mu \mathrm{m})$. Fig. 2 shows the $\mathrm{XRD}$ patterns measured from the coating surface and the sintered bulk, respectively. Both can be identified as cubic fluorite $\mathrm{CeO}_{2}$ phase, indicating that there is no difference in the phase compositions between the coating and the sintered bulk specimens.

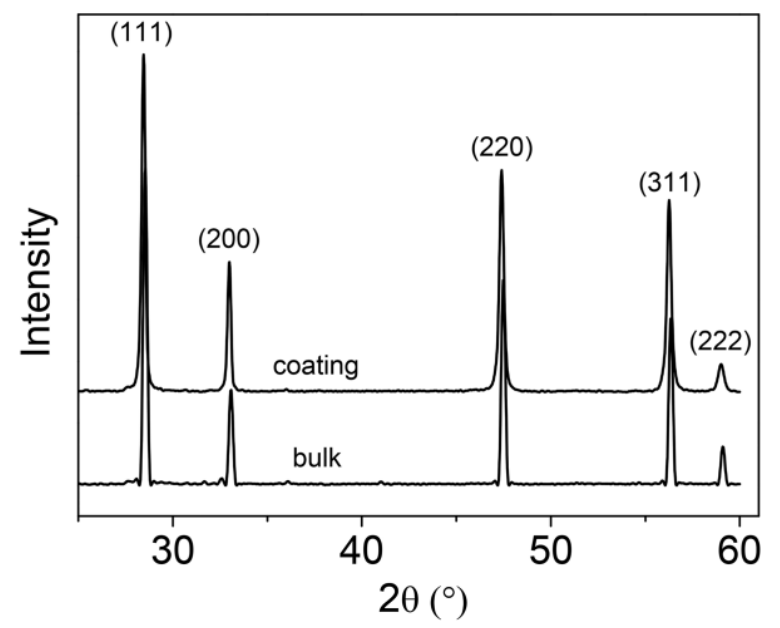

Fig. 2. XRD patterns of the ceria coating and the sintered bulk.

\subsection{Hydrophobicity of the ceria coating}



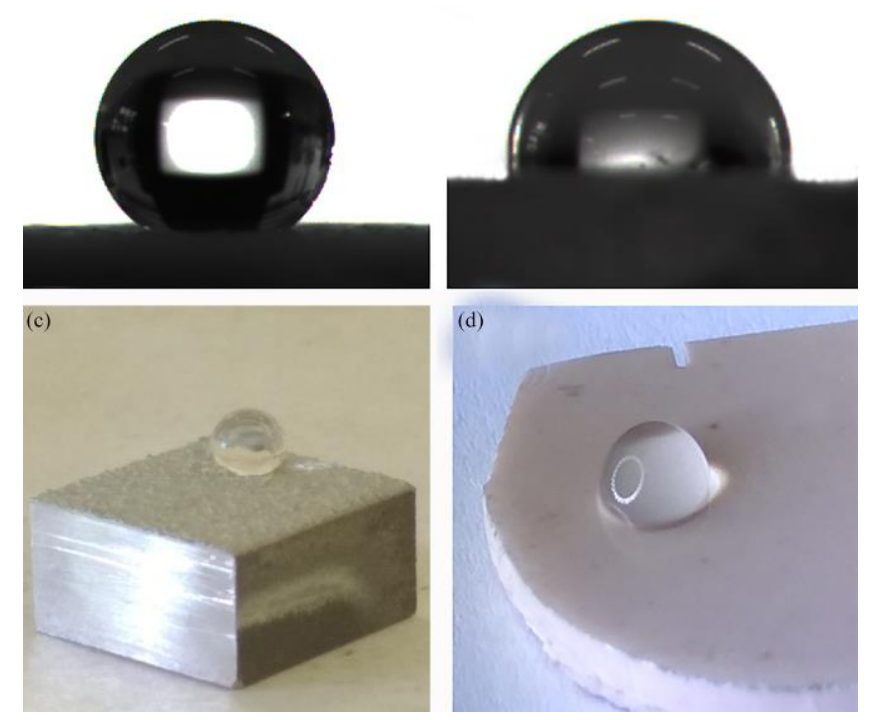

Fig. 3. Optical images of water droplets on the surface of the ceria coating (a and c), the sintered bulk (b and d).

The surface wettability was evaluated using a water contact angle system. Fig. 3 a-d show the photographs of the water droplet on the ceria coating and the sintered bulk. The water contact angle is $139 \pm 3^{\circ}$ is for the plasma sprayed ceria coating, and is $95 \pm$ $2^{\circ}$ for the sintered bulk, implying that the coating is much more hydrophobic than the bulk, though they are fabricated using the same powder and with the same cubic phase. It is well known that the water contact angle would be affected by the surface roughness. To investigate the relationship between roughness and water contact angle, the coating was grinded using different grit papers to create different roughness. Then the water contact angles were re-measured after each grinding. Fig. 4 shows the relationship between the roughness and the water contact angle. As the surface roughness of the coating decreases, the water contact angles decrease from $139 \pm 3^{\circ}$ to $116 \pm 2^{\circ}$. For 
comparison, the water contact angle on the surface of the sintered ceria bulk was also included, which exhibited a water contact angle of about $95 \pm 2^{\circ}$. This clearly demonstrates that the coating is still more hydrophobic than the sintered bulk even the coating was polished, suggesting that the APS process has a significant effect on the hydrophobicity of the ceria materials.

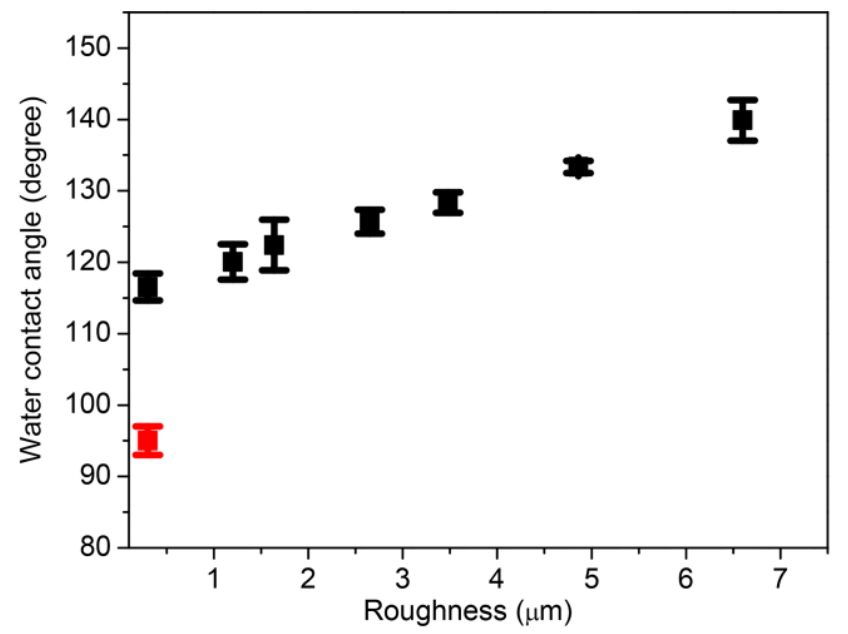

Fig. 4. Relationship between the water contact angles and the roughness for the ceria coating.

The red point at the right bottom represents the sintered bulk.

\subsection{Surface chemistry characterization}
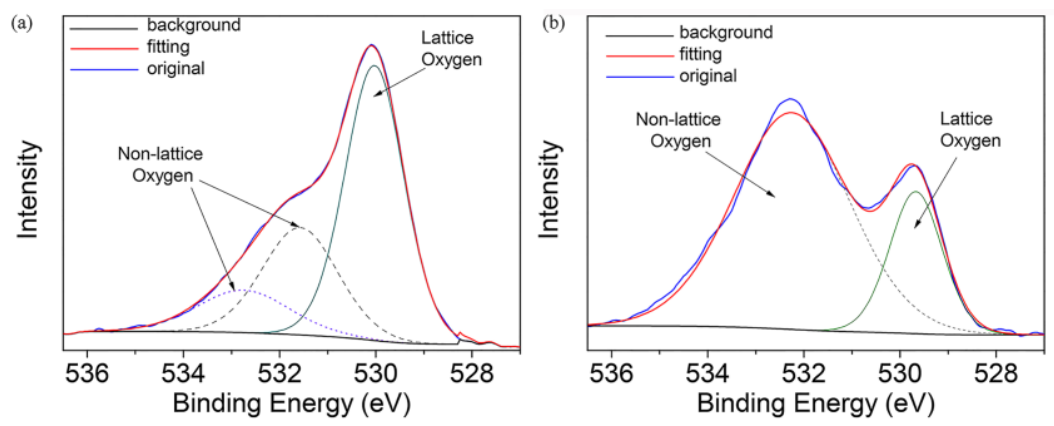

Fig. 5. XPS spectra of oxygen (O 1s). (a) the ceria coating, (b) the sintered ceria bulk. 
To investigate what happened to the ceria coating during the APS process, XPS and FTIR were employed to analyze surface chemistry of the coating and the bulk samples. As shown in Fig. 5, for the coating sample, the spectrum is composed of three photoelectron peaks, which locates at $529.6 \mathrm{eV}, 531.5 \mathrm{eV}$, and $532.9 \mathrm{eV}$, and the relative contents are $57.49 \%, 28.67 \%$, and $13.84 \%$ respectively. The peak at $529.6 \mathrm{eV}$ correspond to lattice oxygen in oxide from the cerium oxide ${ }^{37-39}$. The peak located at $531.5 \mathrm{eV}$ corresponds to the adsorbed hydroxyl species ${ }^{38,40}$. The peak at $532.9 \mathrm{eV}$ is associated with adsorbed molecular water ${ }^{38,39,41}$. Whereas for the bulk specimen fabricated by sintering, the spectrum is composed of two photoelectron peaks, which locates at $529.7 \mathrm{eV}$ and $532.3 \mathrm{eV}$. The peak at $529.7 \mathrm{eV}$ correspond to lattice oxygen in oxide from the cerium oxide ${ }^{37-39}$. The peak at $532.3 \mathrm{eV}$ is attributed to hydroxyl groups or adsorbed molecular water ${ }^{40-42}$. The relative contents of the peak at $529.7 \mathrm{eV}$ and the peak at $532.3 \mathrm{eV}$ are $22.9 \%$ and $77.1 \%$ respectively. Compared to the sintered bulk, the plasma sprayed coating contains less non-lattice oxygen, which means the coating adsorbs less hydroxyl species and molecular water. The argument was supported from the FT-IR measurement. As shown in Fig. 6, the transmittance signal around $3500 \mathrm{~cm}^{-}$ ${ }^{1}$ was observed. The signal is caused by the surface $\mathrm{OH}-$ group ${ }^{43}$. Apparently, the coating adsorb less moisture than the bulk, which agrees with the XPS results. 


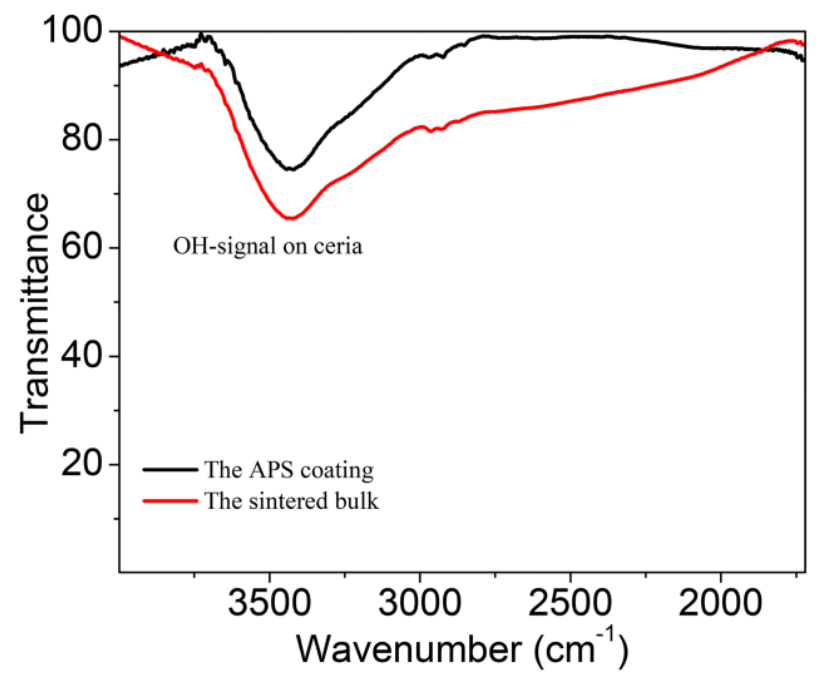

Fig. 6. FTIR spectra of the sintered bulk and the APS coating.

\subsection{Thermal stability of the hydrophobic ceria coating}

To evaluate the thermal stability of the hydrophobic ceria coating, the coating was annealed at $773 \mathrm{~K}$ for 2 hours in the air, and cooled in the furnace to the room temperature. After annealing, the coating maintains the hydrophobicity with a water contact angle of $131 \pm 3^{\circ}$, which shows the ceria coating has good thermal stability and the coating is robust.

\section{Discussion}

The results obtained from this study clearly demonstrated that the plasma sprayed ceria coating exhibited a quasi-superhydrophobicity with a water contact angle up to 139 degree, significantly higher than that of the sintered bulk. It is well known that hydrophobicity is governed by the surface roughness and chemistry ${ }^{6,44}$. As shown in Fig. 4, the water contact angle for the as-sprayed coating $\left(\sim 139^{\circ}\right)$ is $23^{\circ}$ higher than the 
polished coating $\left(\sim 116^{\circ}\right)$, which is attributed to the roughness effect. In addition, compared with the sintered bulk, the water contact angle for the coating with the same roughness is about $21^{\circ}$ higher, which can be attributed to the chemistry effect induced by the plasma spraying. Both effects have significant contribution to the hydrophobicity of the coating.

According to Young's equation ${ }^{45}$, the surfaces with low surface energy tend to be more hydrophobic than those with high surface energy. To explain the roughness effect, the Wenzel model is considered ${ }^{25}$. In this model, the apparent contact angle $\left(\theta_{w}\right)$ on a rough surface in a homogeneous regime is expressed as:

$\cos \theta_{w}=r(\cos \theta)$

where $\theta$ is the contact angle on the flat surface, and $\mathrm{r}$ is the roughness ratio, defined as the ratio of the true area of the solid surface to its projection area. Since the $r$ is always large than $1, \theta_{w}$ will be higher than $\theta$ if the surface is intrinsically hydrophobic. The APS coatings forms a rougher surface with dual scale structures as shown in Fig. 1,which are similar to the surface structures of lotus leaf, overwhelmingly contribute to the hydrophobic feature ${ }^{44}$.

However, as shown in Fig. 4, the water contact angle of the coating is still much higher than that of the bulk even the ceria coating was polished. The reason is ascribed to the effect of APS process, which can change the amount of non-lattice oxygen in ceria. It should be noted that the non-lattice oxygen is related to adsorbed hydroxyl or water molecule ${ }^{38-42}$. The strong tendency to adsorb moisture leads to a higher amount of 
hydrogen-bonded oxygen $(\mathrm{O}-\mathrm{H})$ groups on surfaces, i.e., hydrophilic. FTIR spectra shown in Fig. 6 also indicate that the bulk is tend to adsorb moisture compared to the APS coating.

Previous reports have demonstrated that the $\mathrm{O} / \mathrm{Ce}$ ratio is a key factor to influence the hydrophobicity ${ }^{39}$. The higher oxygen amount is, the more likely to form hydrogen bonds with interfacial water on the surface, which benefits to wettability. Martínez et al demonstrated that the $\mathrm{O} / \mathrm{Ce}$ ratio decreased after the ceria was bombed by the $\mathrm{Ar}^{+}$ ion $^{38}$. During the APS process, the ceria powders were bombed by the $\mathrm{Ar}^{+}$ion. To investigate this point, $\mathrm{Ar}^{+}$ion bombing experiments were performed on the surface of sintered bulk. Then both the water contact angle and surface chemical state was evaluated. As shown in Table 2, with the decreasing of $\mathrm{O} / \mathrm{Ce}$ ratio, the content of the non-lattice oxygen decreases, and the surface become more hydrophobic. After $\mathrm{Ar}^{+}$ion bombard, the ceria bulk become more hydrophobic. Therefore, $\mathrm{Ar}^{+}$ion bombardment caused by APS process makes the coating intrinsically more hydrophobic. It indicated that $\mathrm{Ar}^{+}$ion bombing might be an effective way to increase the hydrophobicity of ceria material.

Table 2 Comparison of $\mathrm{O} / \mathrm{Ce}$ ratio, surface non-lattice oxygen, and water contact angles (WCA) of the bulk and the Ar ${ }^{+}$bombed bulk

\begin{tabular}{llll}
\hline Sample & O/Ce ratio & Surface non-lattice oxygen $(\%)$ & WCA $\left({ }^{\circ}\right)$ \\
\hline Bulk & 4.12 & 77.1 & 95 \\
Bombed bulk & 2.35 & 52.3 & 105 \\
\hline
\end{tabular}


Distinguished from the traditional the organic or organic modified surfaces, the plasma sprayed ceria coating is more thermally stable under harsh environment. Generally the ceramic coating has higher hardness and is more wear resistant. Moreover, the coating can maintain hydrophobicity even after annealed at high temperature. This is because the bond coat circumvents the problem that the coating is spalled after high temperature annealing, which derives from considerable mismatch of the thermal expansion coefficients between ceramic and substrate ${ }^{24,29}$. Hence, the robust APS ceria coating exhibits good thermal stability, which shows promising potential in the application of hydrophobic coating undergoing harsh temperature variation.

\section{Conclusion}

In summary, a robust hydrophobic ceramic coatings were prepared using plasma spraying. The superior wetting ability was attributed to the intrinsic hydrophobicity of ceria, the unique surface morphology and chemistry of the sprayed coating. In addition, the plasma sprayed coating is much more hydrophobic than the sintered bulk with the same composition and the surface roughness, indicating the surface bonding was changed by plasma. XPS and FTIR measurements indicated that the coating surface exhibited a lower O/Ce ratio and less content of non-lattice oxygen. Thus the surface has less tendency to absorb the hydroxyl and molecular water in the air, leading to a higher water contact angle than the sintered bulk.

It was demonstrated that the $\mathrm{Ar}^{+}$ion bombing treatment can increase the WCA of the sintered ceria bulk specimen. Subsequent XPS measurements confirmed that the $\mathrm{Ar}^{+}$ 
bombing reduced the $\mathrm{O} / \mathrm{Ce}$ ratio, due to the decrease of non-lattice oxygen, i.e., absorbed hydroxyl or molecular water on the surface. Therefore, the $\mathrm{Ar}^{+}$ion bombing might offer a new approach to increase the surface wettability of materials.

In addition to ceria, it is suggested that most REOs coating prepared by plasma spraying should have a superior hydrophobicity. As a ceramic material, such coatings have a better wear resistance and high temperature stability than the organic coatings. Therefore, it is believed that the REOs coatings prepared by plasma spraying should have a wide range engineering application, such as power lines and oil-gas pipelines where the hydrophobicity and the robustness are both demanded. 


\section{References}

1. Kuna JJ, Voitchovsky K, Singh C, et al. The effect of nanometre-scale structure on interfacial energy. Nat Mater. 2009; 8, (10), 837-42.

2. Chandler D. Interfaces and the driving force of hydrophobic assembly. Nature. 2005; 437, (7059), 640-7.

3. Zhang X, Zhu Y, Granick S. Hydrophobicity at a Janus interface. Science. 2002; 295, (5555), 663-6.

4. Yao X, Song Y, Jiang L. Applications of bio-inspired special wettable surfaces. Adv Mater. 2011; 23, (6), 719-34.

5. Hu Z, Zhang X, Liu Z, et al. Regulating Water Adhesion on Superhydrophobic TiO2Nanotube Arrays. Adv Funct Mater. 2014; 24, (40), 6381-6388.

6. Li XM, Reinhoudt D, Crego-Calama M. What do we need for a superhydrophobic surface? A review on the recent progress in the preparation of superhydrophobic surfaces. Chem Soc Rev. 2007; 36, (8), 1350-68.

7. Barthlott W, Neinhuis C. Purity of the sacred lotus, or escape from contamination in biological surfaces. Planta. 1997; 202, (1), 1-8.

8. Saito H, Takai K-i, Takazawa H, Yamauchi G. A Study on Snow Sticking Weight To Water-Repellent Coatings. J Soc Mater Sci Jpn. 1997; 46, (12Appendix), 216-219.

9. Hakovirta M, Verda R, He XM, Nastasi M. Heat resistance of fluorinated diamondlike carbon films. Diam Relat Mater. 2001; 10, (8), 1486-1490.

10. Parkin IP, Palgrave RG. Self-cleaning coatings. J Mater Chem. 2005; 15, (17), 1689.

11. Quéré D. Non-sticking drops. Rep Prog Phys. 2005; 68, (11), 2495-2532. 
12. Pan Q, Wang M, Wang H. Separating small amount of water and hydrophobic solvents by novel superhydrophobic copper meshes. Appl Surf Sci. 2008; 254, (18), 6002-6006.

13. Boreyko JB, Collier CP. Delayed frost growth on jumping-drop superhydrophobic surfaces. ACS NANO. 2013; 7, (2), 1618-27.

14. Maitra T, Tiwari MK, Antonini $\mathrm{C}$, et al. On the nanoengineering of superhydrophobic and impalement resistant surface textures below the freezing temperature. Nano Lett. 2014; 14, (1), 172-82.

15. Tadanaga $\mathrm{K}$, Morinaga $\mathrm{J}$, Matsuda A, Minami $\mathrm{T}$. Superhydrophobic-Superhydrophilic Micropatterning on Flowerlike Alumina Coating Film by the Sol-Gel Method. Chem Mater. 2000; 12, (3), 590-592.

16. Levkin PA, Svec F, Frechet JM. Porous polymer coatings: a versatile approach to superhydrophobic surfaces. Adv Funct Mater. 2009; 19, (12), 1993-1998.

17. Bocquet L, Lauga E. A smooth future? Nat Mater. 2011; 10, (5), 334-7.

18. Fredj N, Cohendoz S, Feaugas X, Touzain S. Effect of mechanical stress on kinetics of degradation of marine coatings. Prog Org Coat. 2008; 63, (3), 316-322.

19. Lai Y, Tang Y, Gong J, et al. Transparent superhydrophobic/superhydrophilic TiO2based coatings for self-cleaning and anti-fogging. J Mater Chem. 2012; 22, (15), 7420. 20. Zheng JY, Bao SH, Guo Y, Jin P. Natural hydrophobicity and reversible wettability conversion of flat anatase $\mathrm{TiO}(2)$ thin film. ACS Appl Mater Inter. 2014; 6, (3), 13515.

21. Haapanen J, Aromaa M, Teisala H, et al. Binary TiO2/SiO2 nanoparticle coating 
for controlling the wetting properties of paperboard. Mater Chem Phys. 2015; 149-150, 230-237.

22. Feng X, Feng L, Jin M, Zhai J, Jiang L, Zhu D. Reversible super-hydrophobicity to super-hydrophilicity transition of aligned $\mathrm{ZnO}$ nanorod films. J Am Chem Soc. 2004; $126,(1), 62-3$.

23. Zhao Y, Xie S, Jiang Y. The superhydrophobic properties of $\mathrm{ZrO} 2$ induced by laser irradiation. Surf Interface Anal. 2012; 44, (10), 1360-1363.

24. Azimi G, Dhiman R, Kwon HM, Paxson AT, Varanasi KK. Hydrophobicity of rareearth oxide ceramics. Nat Mater. 2013; 12, (4), 315-20.

25. Wenzel RN. Resistance of solid surfaces to wetting by water. Ind Eng Chem. 1936.

26. Cassie ABD, Baxter S. Wettability of porous surfaces. Transactions of the Faraday Society. 1944; 40, 546.

27. Quéré D. Wetting and Roughness. Annu Rev Mater Res. 2008; 38, (1), 71-99.

28. Zenkin S, Kos Š, Musil J, Rohrer G. Hydrophobicity of Thin Films of Compounds of Low-Electronegativity Metals. J Am Ceram Soc. 2014; 97, (9), 2713-2717.

29. Oh I-K, Kim K, Lee Z, et al Hydrophobicity of Rare Earth Oxides Grown by Atomic Layer Deposition. Chem Mater. 2015; 27, (1), 148-156.

30. Cho YJ, Jang H, Lee K-S, Kim DR. Direct growth of cerium oxide nanorods on diverse substrates for superhydrophobicity and corrosion resistance. Appl Surf Sci. $2015 ; 340,96-101$.

31. An T, Deng X, Liu S, Wang S, Ju J, Dou C. Growth and roughness dependent wetting properties of $\mathrm{CeO} 2$ films prepared by glancing angle deposition. Ceram Int. 
2018; 44, (8), 9742-9745.

32. An T, Deng X, Gao Y, Liu S, Dou C, Ju J. Preparation of highly hydrophobic CeO2 films using glancing angle deposition. Mater Lett. 2018; 216, 147-149.

33. Tam J, Palumbo G, Erb U, Azimi G. Robust Hydrophobic Rare Earth Oxide Composite Electrodeposits. Adv Mater Interfaces. 2017; 4, (24), 1700850.

34. Lakhotia SR, Mukhopadhyay M, Kumari P. Cerium oxide nanoparticles embedded thin-film nanocomposite nanofiltration membrane for water treatment. Sci Rep. 2018; 8, (1), 4976.

35. Padture NP, Gell M, Jordan EH. Thermal barrier coatings for gas-turbine engine applications. Science. 2002; 296, (5566), 280-4.

36. Stroosnijder MF, Guttmann V, Fransen T, de Wit JHW. Corrosion of alloy $800 \mathrm{H}$ and the effect of surface-applied $\mathrm{CeO} 2$ in a sulphidizing/oxidizing/carburizing environment at $700^{\circ} \mathrm{C}$. Oxid met. 1990; 33, (5-6), 371-397.

37. Force C, Roman E, Guil JM, Sanz J. XPS and 1H NMR study of thermally stabilized $\mathrm{Rh} / \mathrm{CeO} 2$ catalysts submitted to reduction/oxidation treatments. Langmuir. 2007; 23, (8), 4569-74.

38. Martínez L, Román E, de Segovia JL, Poupard S, Creus J, Pedraza F. Surface study of cerium oxide based coatings obtained by cathodic electrodeposition on zinc. Appl Surf Sci. 2011; 257, (14), 6202-6207.

39. Khan S, Azimi G, Yildiz B, Varanasi KK. Role of surface oxygen-to-metal ratio on the wettability of rare-earth oxides. Appl Phys Lett. 2015; 106, (6), 061601.

40. Fan J, Wu X, Yang L, Weng D. The SMSI between supported platinum and CeO2- 
ZrO2-La2O3 mixed oxides in oxidative atmosphere. Catal Today. 2007; 126, (3-4), 303-312.

41. Hamoudi S, Larachi F, Adnot A, Sayari A. Characterization of Spent MnO2/CeO2 Wet Oxidation Catalyst by TPO-MS, XPS, and S-SIMS. J Catal. 1999; 185, (2), 333 344.

42. Mora N, Cano E, Polo JL, Puente JM, Bastidas JM. Corrosion protection properties of cerium layers formed on tinplate. Corros Sci. 2004; 46, (3), 563-578.

43. Yalamanchili MR, Atia AA, Miller JD. Analysis of Interfacial Water at a Hydrophilic Silicon Surface by in-Situ FTIR/Internal Reflection Spectroscopy. Langmuir. 1996; 12, (17), 4176-4184.

44. Feng L, Li S, Li Y, et al. Super-Hydrophobic Surfaces: From Natural to Artificial. Adv Mater. 2002; 14, (24), 1857-1860.

45. Young T. An Essay on the Cohesion of Fluids. Philosophical Transactions of the Royal Society of London. 1805; 95, (0), 65-87. 